\title{
Beyond Plate Tectonics: Looking at Plate Deformation with Space Geodesy
}

\author{
THOMAS H. JORDAN \\ Department of Earth, Atmospheric and Planetary Sciences \\ Massachusetts Institute of Technology, Cambridge, MA 02139 \\ J. BERNARD MINSTER \\ Institute of Gecphysics and Planetary Physics \\ Scripps Institution of Oceanography \\ La Jolla, CA 92093
}

\begin{abstract}
We address the requirements that must be met by space-geodetic systems to place useful, new constraints on horizontal secular motions associated with the geological deformation of the earth's surface. Plate motions with characteristic speeds of about 50 $\mathrm{mm} / \mathrm{yr}$ give rise to displacements that are easily observed by space geodesy. However, in order to improve the existing plate-motion models, the tangential components of relative velocities on interplate baselines must be resolved to an accuracy of $<3 \mathrm{~mm} / \mathrm{yr}$. Because motions considered small from a geodetic point of view have rather dramatic geological effects, especially when taken up as compression or extension of continental crust, detecting plate deformation by space-geodetic methods at a level that is geologically unresolvable places rather stringent requirements on the precision of the measurement systems: the tangential components on intraplate baselines must be observed with an accuracy of $<1 \mathrm{~mm} / \mathrm{yr}$. Among the measurements of horizontal secular motions that can be made by space geodesy, those pertaining to the rates within the broad zones of deformation characterizing the active continental plate boundaries are the most difficult to obtain by conventional ground-based geodetic and geological techniques. Measuring the velocities between crustal blocks to $\pm 5 \mathrm{~mm} / \mathrm{yr}$ on $100-\mathrm{km}$ to $1000-\mathrm{km}$ length scales can yield geologically significant constraints on the integrated deformation rates across continental plate-boundary zones such as the western United States. However, baseline measurements in geologically complicated zones of deformation are useful only to the extent that the endpoints can be fixed in a local kinematical frame that includes major crustal blocks. For this purpose, the establishment of local geodetic networks around major VLBI and SLR sites in active areas should receive high priority.
\end{abstract}

\section{INTRODUCTION}

Deformation of the earth's lithosphere covers a broad spectrum of temporal and spatial scales, from seconds to aeons and from mineral grains to planetary dimensions. Table 1 categorizes a subset of lithospheric motions that cause geologically and geophysically significant deformations. It is convenient to discriminate secular motions persisting on 
geological time scales of thousands to millions of years from transients associated with, for example, seismic and volcanic events. Practical research is more concerned with the transients, because they tend to disturb human activities. Secular motions also warrant vigorous study, however, since they provide the kinematical framework for describing transients and understanding their driving mechanisms.

TABLE 1. Types of motions observed at the earth's surface.

\begin{tabular}{lll}
\hline & \multicolumn{1}{c}{ SECULAR } & \multicolumn{1}{c}{ TRANSIENT } \\
\hline HORIZONTAL & $\begin{array}{ll}\text { Plate motions } \\
\text { Boundary-zone tectonics } \\
\text { Intraplate deformation }\end{array}$ & $\begin{array}{l}\text { (Pre,co,post)-seismic } \\
\text { Fault creep } \\
\text { Stress redistribution }\end{array}$ \\
& Tectonic motions & $\begin{array}{l}\text { (Pre,co,post)-seismic } \\
\text { Magma inflation }\end{array}$ \\
& Thermal subsidence & Tidal loading \\
DeRTICAL & Crustal loading & \\
& Post-glacial rebound & \\
& Cratonic epeirogeny & \\
\hline
\end{tabular}

The most significant long-term deformations are those related to plate tectonics. Although local tectonic movements near plate boundaries display large vertical components and time-dependent behavior, the net motions between the stable interiors of large blocks are forced by viscous damping and gravity to be nearly steady and horizontal. The characteristic tangential velocity of the plate system is about $50 \mathrm{~mm} / \mathrm{yr}$, which gives rise to displacements easily measured by geodetic methods. Horizontal secular motions have been observed both by ground-based networks [e.g., Savage, 1983] and by space-geodetic systems [e.g., Christodoulidis et al., 1985; Herring et al., 1986]. Though their application to geodesy is relatively new, space-based techniques -- Very Long Baseline Interferometry (VLBI), Satellite Laser Ranging (SLR), Global Positioning System (GPS) -- have already revolutionized the science of terrestrial distance measurement. They are contributing new information about active tectonics, particularly on the planetary scales previously inaccessible to ground-based surveys (Figure 1).

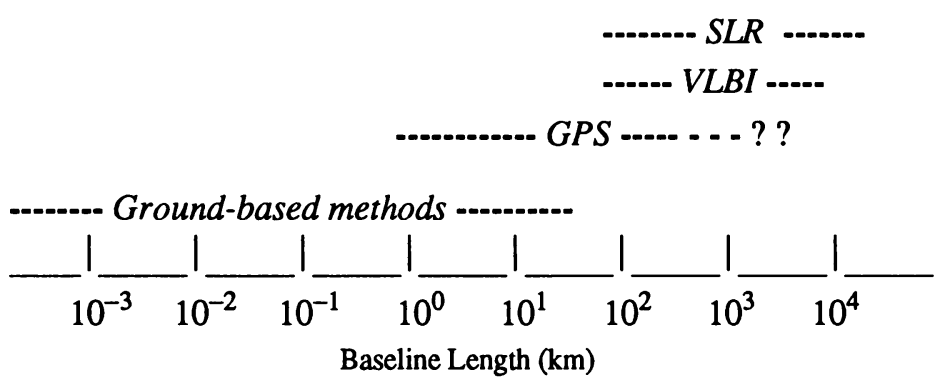

Figure 1. Spatial scales sampled by various geodetic methods. 
In this paper, we examine the space-geodetic observations needed to solve geologically interesting problems. Specifically, we are concerned with the measurement accuracy required to place useful, new constraints on models of global plate velocities and related horizontal secular motions.

\section{Plate Motions}

In the ocean basins, most of the deformation related to horizontal secular motion occurs in well-defined, narrow zones that are the boundaries of a dozen or so large lithospheric plates. The current plate velocities are constrained by three basic types of data collected along these submerged boundaries: (1) spreading rates on mid-ocean ridges from magnetic anomalies, and directions of relative motion from (2) transform-fault azimuths and (3) earthquake slip vectors. The first self-consistent global models were synthesized soon after the formulation of plate tectonics [Le Pichon, 1968], and significant refinements were made throughout the next decade [Chase, 1972; Minster et al., 1974]. Third-generation models were published by 1978 [Chase, 1978; Minster and Jordan, $1978]$ and are still in use. The velocity field for the RM2 model of Minster and Jordan [1978] is depicted in Figure 2.

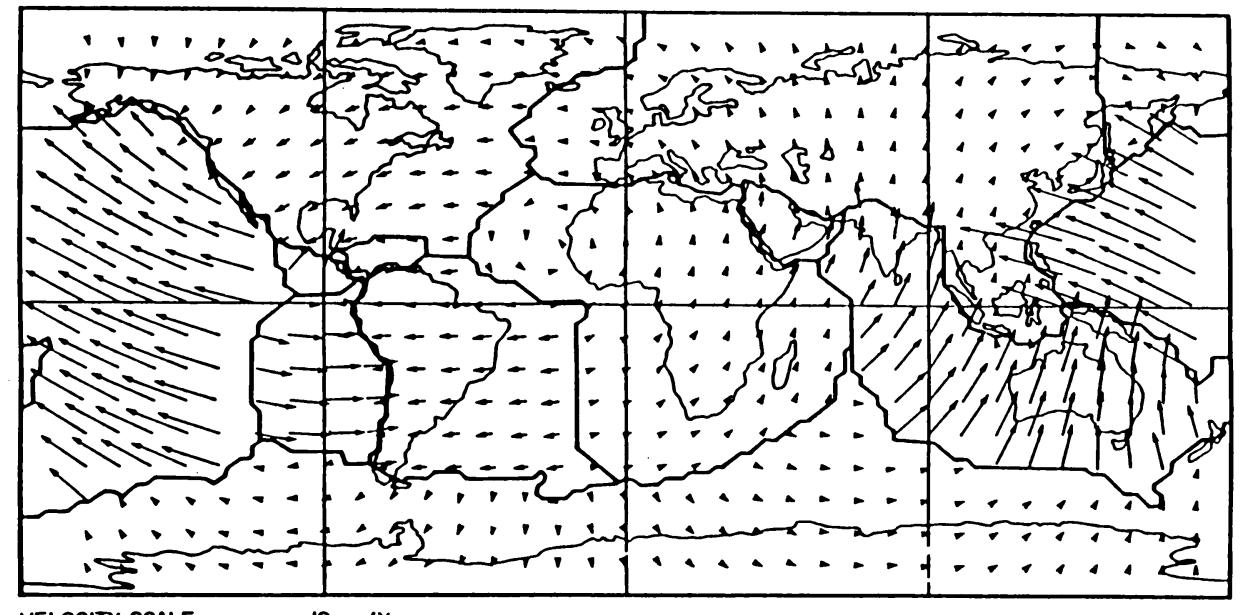

VELOCITY SCALE: $\longrightarrow=10 \mathrm{~cm} /$ Yr

Figure 2. The plate geometry and velocity field for the eleven-plate RM2 model of Minster and Jordan [1978] in the AM1-2 (hotspot) reference frame (map courtesy of A. Forte and W. Peltier).

Since the reference frame is arbitrary, the angular velocity vectors describing the instantaneous relative motions among $M$ rigid plates are specified by $3(M-1)$ independent components. The 30 numbers representing the eleven-plate RM2 model were derived by least-squares inversion of a carefully selected, globally distributed data set comprising 110 spreading rates, 78 fault azimuths, and 142 slip vectors. The magnetic anomalies employed in this analysis average the rates over the last 2-3 million years, about the shortest time span for which good spreading rates can be obtained on a global basis. 
Although the interval sampled by RM2 is hardly "instantaneous" from a geodetic point of view, it is geologically brief, and the small plate displacements that take place during it are well described by infinitesimal (as opposed to finite) rotations.

TABLE 2. Comparison of extension rates, in $\mathrm{mm} / \mathrm{yr}$, for two transatlantic baselines.

\begin{tabular}{lcc}
\hline Baseline & VLBI $^{*}$ & RM2 $^{\dagger}$ \\
\hline Haystack-Onsala & $17 \pm 2$ & $17 \pm 3$ \\
Ft.Davis-Onsala & $20 \pm 7$ & $16 \pm 3$ \\
\hline
\end{tabular}

* CDP/IRIS data from Herring et al. [1986].

$\dagger$ Calculated for NOAM-EURA plate pair.

It will probably be some time before the global plate-tectonic models can be significantly improved by space geodesy. Because the geological data sets are large and the inverse problem is strongly overdetermined, the formal uncertainties in the angular velocity components are already fairly small. RM2 predicts interplate baseline rates-of-change with standard errors that are typically a few millimeters per year $(\mathrm{mm} / \mathrm{yr})$ [Minster and Jordan, 1983]. Consider, for example, the two transatlantic baselines in Table 2, which connect the VLBI antenna at Onsala, Sweden, with antennas in Massachusetts and Texas. Positions between these sites have been measured at relatively frequent intervals under the auspices of the International Radio Interferometric Surveying (IRIS) project and NASA's Crustal Dynamics Project (CDP). From an analysis of the 1980-1984 data, Herring et al. [1986] have found rates of motion between the Eurasian and North America plates that are in good agreement with the RM2 estimates. This is comforting, both as a check on the techniques and as corroboration of the geophysical expectation that the instantaneous velocities between points in stable plate interiors are dominated by secular plate motions. However, if the 3-mm/yr prediction errors of the plate model can be believed, high-quality VLBI data sets over a number of such baselines will be needed to really refine the geological estimates.

There are other plate pairs for which the currently available global models are not as good, and some improvement could be made from space-geodetic data. In Figure 2, for example, Southeast Asia is assumed to be part of the large Eurasian plate, but the active tectonics of China imply it should be moving as a separate entity. Because it is completely surrounded by complex zones of deformation, its motion relative to Eurasia will be difficult to quantify without space-geodetic observations. Closer to home is the case of the Pacific-North America plate pair, whose relative rate of motion can be directly measured only on a tiny ridge segment in the mouth of the Gulf of California. From a reanalysis of the magnetic anomaly profiles across this ridge by DeMets et al. [1987], it appears that previous estimates of the spreading rate made by us and others were biased high by about $15-20 \%$, and standard models like RM2 overestimate the relative plate speed. Since this rate is critical to models of deformation in the western United States (see below), a geodetic check on the Pacific-North America angular velocity will be very valuable.

With these exceptions and a few others, however, the global networks of VLBI and 
SLR stations are just too sparse to control plate motions as tightly as the geological observations. Work is nearing completion at Northwestern University on an improved fourth-generation plate-motion model ( $R$. Gordon, personal communication, 1987), which should remedy the few problems thus far identified with RM2. The impact of geodetic observations on the development of these plate-motion standards will be relatively minor, at least for the next few years.

Of course, this does not say that interplate observations made by space-geodetic methods will not reveal new and interesting phenomena associated with other categories of motion listed in Table 1; particular attention should be focused on time-dependent signals, including the possibility that plate speeds and directions have changed significantly during the 2-My averaging period of the geological data. Our point is to emphasize that the exciting issues for space geodesy lie beyond the now-classical descriptions of major plate motions.

\section{DEFORMATION OF PLATE-BOUNDARY ZONES}

In particular, space geodesy can be used to quantify models of the complex deformation that characterizes all major continental plate boundaries. In the western United States, the interaction between the North America plate and northwestward moving Pacific plate is spread out over a $1000-\mathrm{km}$ wide zone of deformation, stretching from the Rocky Mountains to the continental margin. Although California's San Andreas Fault is the major locus of movement on the plate boundary, the likelihood that significant crustal deformation is occuring both east and west of the fault has long been recognized by geologists. Reliable constraints on the rates of deformation integrated across regions with characteristic dimensions of $100 \mathrm{~km}$ or more are critical for understanding fundamental tectonic processes and assessing seismogenic potential. Rates of motion in continental regions are notoriously difficult to pin down by geological methods alone, and at this scale, ground-based geodetic surveys are expensive and inaccurate. Space geodesy appears to be the most feasible methodology.

VLBI measurements have already established significant constraints on geological motions in the Basin and Range Province, a peculiar region of diffuse seismicity and ubiquitous vulcanism which encompasses the Great Basin of Nevada and western Utah. A variety of geological and geophysical data indicate that the Basin and Range is stretching along an axis oriented approximately $\mathrm{N} 60^{\circ} \mathrm{W}$ [Zoback and Zoback, 1980], but the rate of opening has been the subject of a long-standing controversy. In some cases the slip rates on individual faults have been inferred from detailed paleoseismic mapping [Wallace, 1984], but very few have been studied well enough to establish more than crude bounds. Geological estimates integrated across the entire province range from as low as $1 \mathrm{~mm} / \mathrm{yr}$ to as high as $22 \mathrm{~mm} / \mathrm{yr}$, with a probable value in the range $4-12 \mathrm{~mm} / \mathrm{yr}$ [Minster and Jordan, $1984,1987]$. Unlike the case of global plate motions discussed above, the assumptions that go into deriving these estimates are questionable, and the data redundancy is low.

In a recent analysis of western U.S. deformation [Minster and Jordan, 1987], we have used 4-yr VLBI rates for seven baselines spanning the Basin and Range to derive the vector motion $\mathbf{v}_{\mathrm{CN}}$ of the aseismic Sierra Nevada-Great Valley block relative to stable North America. We express this motion by a vector $\mathbf{v}_{\mathrm{CN}}$ obtained by extrapolating the relative velocity field of the block to a fiducial point $C$, fixed at a particular (though arbitrary) location on the San Andreas Fault in central California; our conventional choice, adopted here, is at $36^{\circ} \mathrm{N}, 120.6^{\circ} \mathrm{W}$. The VLBI data alone gives an estimate of $9 \pm 4$ $\mathrm{mm} / \mathrm{yr}, \mathrm{N} 48 \pm 17^{\circ} \mathrm{W}$ at point $C$ (Figure 3 , left panel). When the geological constraints on the azimuth of the opening are combined with the VLBI rates, this estimate becomes $10 \pm 2$ 
$\mathrm{mm} / \mathrm{yr}$ at $\mathrm{N} 56 \pm 10^{\circ} \mathrm{W}$ (right panel). Although the formal errors of the estimate should be regarded with appropriate caution, the precision achieved from such a short observing period is impressive.

The VLBI value of $\mathbf{v}_{\mathrm{CN}}$ can be combined with the slip vector $\mathbf{v}_{\mathrm{SA}}$ across the San Andreas, known from ground-based geodetic data and geological mapping, and the total Pacific-North America plate motion $\mathbf{v}_{\mathrm{PN}}$ to derive a residual vector $\mathbf{v}_{\mathrm{CP}}=\mathbf{v}_{\mathrm{CN}}+\mathbf{v}_{\mathrm{SA}}-\mathbf{v}_{\mathrm{PN}}$, which measures the deformation west of the San Andreas. (All of these velocities are computed at the fiducial point $C$.) The geometry of this vector closure equation is shown in Figure 4. If RM2 is used to estimate $\mathbf{v}_{\mathrm{PN}}$, the magnitude of $\mathbf{v}_{\mathrm{CP}}$ is $15 \mathrm{~mm} / \mathrm{yr}$ (Figure 3), implying considerable deformation across the California margin. The revised Pacific-North America rate of DeMets et al. [1987] reduces this discrepancy to about 8 $\mathrm{mm} / \mathrm{yr}$, a smaller but nevertheless substantial value. The vector $\mathbf{v}_{\mathrm{CP}}$ can be resolved into two parts: a component of right-lateral shear parallel to the California coastline, which is presumably taken up on the largely offshore San Gregorio-Hosgri fault system, and a component of compression perpendicular to the coastline, which may be distributed across a region extending from the Great Valley east of the San Andreas to the edge of the continental margin [Gawthrop, 1978; Crouch et al., 1984; Minster and Jordan, 1984, 1987]. If this model of the deformation is correct, the seismogenic potential of the California margin is likely to be higher than previously thought.
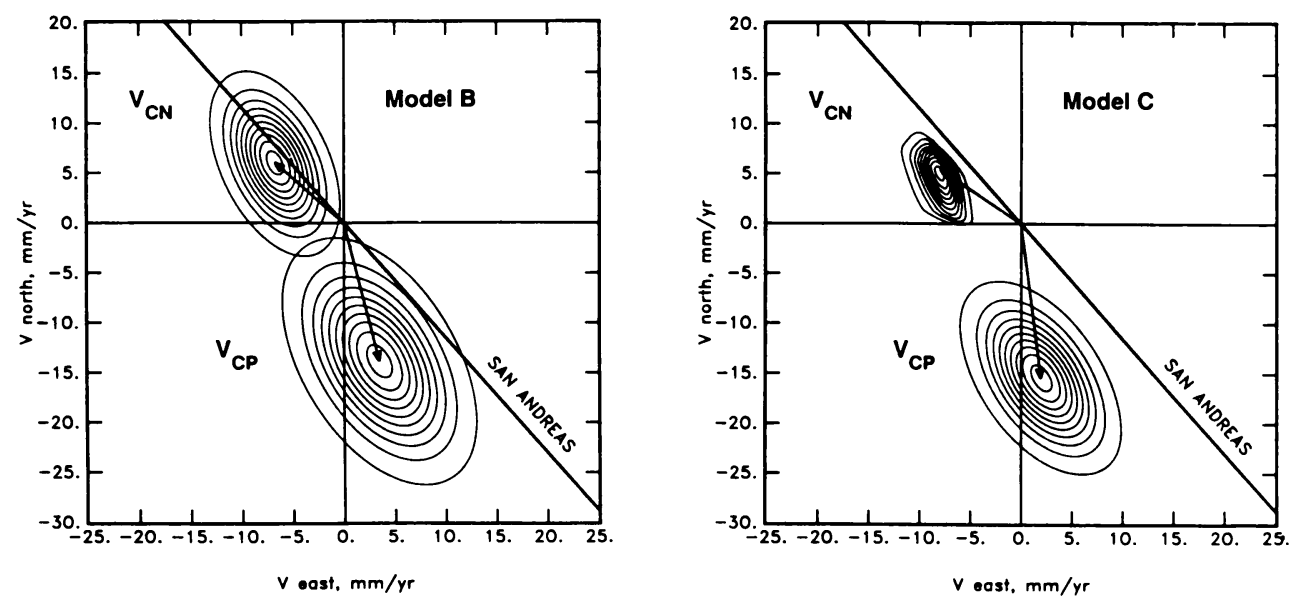

Figure 3. Maximum-likelihood estimates of the Basin and Range opening-rate vector $\mathbf{v}_{\mathrm{CN}}$ derived from VLBI rates-of-change on seven baselines (left panel) and from a combination of VLBI rates and geological azimuths (right panel). Contours delimit the 5\% through $95 \%$ confidence regions in $10 \%$ increments, calculated by the Bayesian procedure of Minster and Jordan [1987]. The residual vector $\mathbf{v}_{\mathrm{CP}}$ describes deformation west of the San Andreas and is computed as the sum $\mathbf{v}_{\mathrm{CN}}+\mathbf{v}_{\mathrm{SA}}-\mathbf{v}_{\mathrm{PN}}$, where $\mathbf{v}_{\mathrm{SA}}$ is the San Andreas slip vector $\left(34 \pm 3 \mathrm{~mm} / \mathrm{yr}, \mathrm{N} 41 \pm 2^{\circ} \mathrm{W}\right)$ and $\mathrm{v}_{\mathrm{PN}}$ is the RM2 Pacific-North America velocity (56 $\left.\pm 3 \mathrm{~mm} / \mathrm{yr}, \mathrm{N} 35 \pm 2^{\circ} \mathrm{W}\right)$. All vectors correspond to velocity fields extrapolated to a fiducial point $C$ at $36^{\circ} \mathrm{N}, 120.6^{\circ} \mathrm{W}$. 
In view of the large population and critical facilities that could be affected by earthquakes near the coast, tests of such speculations by direct geodetic measurements are urgently needed. VLBI and SLR stations along the California coast are beginning to yield baseline rates with the precision required to evaluate competing hypotheses [Lyzenga et al., 1986; Clark et al., 1986; Christodoulidis et al., 1987], but the small number of sites leaves serious gaps in the coverage and does not provide adequate redundancy. The best way to remedy this deficiency is to densify the VLBI and SLR networks with portable GPS instruments. To this end, a consortium of universities is cooperating with several government agencies to set up a GPS network in southern and central California [Agnew et al., 1987]. Included in this network are a number of islands in the Santa Barbara Channel and Southern California Borderlands, which will permit the observation of deformation associated with offshore faulting.

In the western U.S., geologically useful information has been derived from space-geodetic data with rate uncertainties for individual baselines on the order of \pm 5 $\mathrm{mm} / \mathrm{yr}$. The kinematical complexities and seismic hazards of the Pacific-North America plate-boundary zone are by no means unique. The Mediterranean, Middle East, and of course China all display broad belts of tectonic activity, reflecting the relatively low yield strength of the upper continental lithosphere. These and other regions provide ample opportunities to employ the current capabilities of space geodesy as a tool for geological and geophysical investigation.

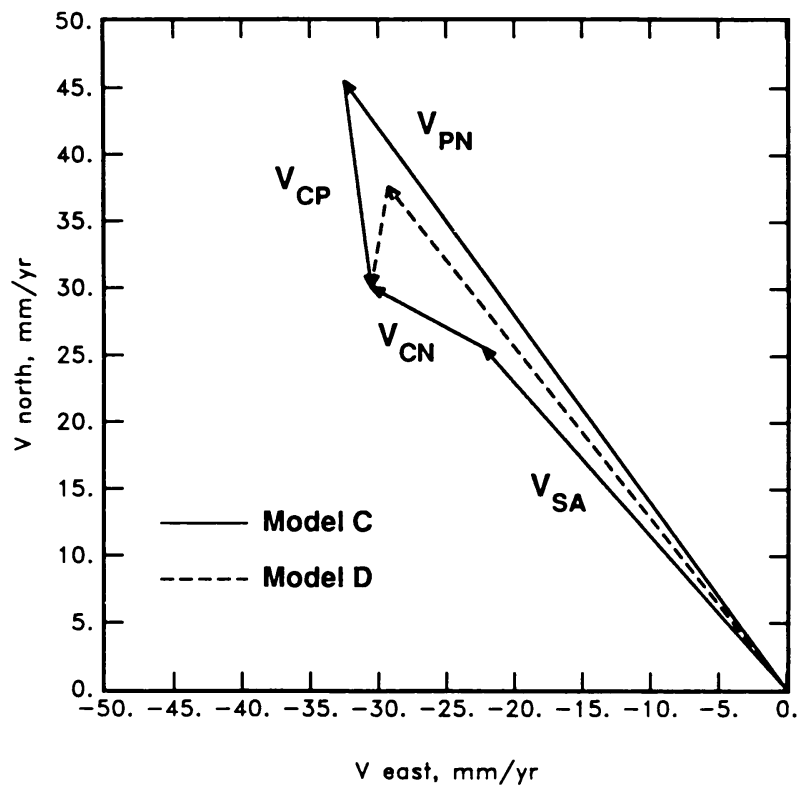

Figure 4. Vector closure diagram for western U.S. deformation showing the contributions of San Andreas slip $\left(v_{S A}\right)$ and deformation east $\left(v_{C N}\right)$ and west $\left(v_{C P}\right)$ of the San Andreas to Pacific-North America relative motion $\left(v_{\mathrm{PN}}\right)$. The solid line uses the RM2 estimate of $\mathbf{v}_{\mathrm{PN}}$, whereas the dashed line employs a relative velocity consistent with a revised spreading rate [DeMets et al., 1987] and fault azimuths [Goff et al., 1987] in the Gulf of California. 


\section{INTRAPLATE DEFORMATIONS}

Plate tectonics is only an idealization. If wide zones of deformation extend away from continental plate boundaries, what about deformations within the supposedly stable plate interiors? An obvious application of space geodesy, and a stated objective of the Crustal Dynamics Project, is to evaluate the accuracy of the rigid-plate approximation. In designing plate-stability experiments, however, it should be realized that motion considered small from a geodetic point of view has rather dramatic geological effects, especially when it is taken up as compression or extension of continental crust. Detecting plate deformation by geodetic methods at a level that is geologically unresolvable will places rather stringent requirements on the precision of space-based measurement systems.

An example of this fact is the spectacular Rio Grande Rift of New Mexico, formed by Neogene extension related to Basin-and-Range opening on the other side of the Colorado Plateau. The rates of deformation across this obviously active, $50-\mathrm{km}$-wide feature have been estimated by both geological and ground-based geodetic techniques, and they are low. Woodward [1977] suggests a rate of only $0.3 \mathrm{~mm} / \mathrm{yr}$ for the expansion of Albuquerque-Belen basin over the last $27 \mathrm{My}$, and Golombeck [1981] estimates an even lower rate for the opening of the Velarde graben since 1.1 My ago. Savage et al. [1980] did not resolve any strain across the rift near Socorro, New Mexico, during the 1972-1979 trilateration surveys, placing an upper bound of $1 \mathrm{~mm} / \mathrm{yr}$ (95\% confidence level) on the integrated strain rate. Hence, the motion across the Rio Grande Rift is small enough that it is usually ignored in discussions of how the Pacific-North America plate motion is partitioned across the western U.S. zone of deformation [Minster and Jordan, 1984].

Compression at this rate will lead to even more impressive features. Because continental crust is buoyant and cannot easily be remixed into the mantle, a secular horizontal shortening will cause it to pile up; $1 \mathrm{~mm} / \mathrm{yr}$ across a width of $50 \mathrm{~km}$ thickens the crust at a rate of about $5 \mathrm{~km}$ every 10 million years, enough to build a sizable topographic expression in (geologically) short order. In fact, the uplift rate of the high Himalayas is only about an order of magnitude greater than this value; i.e., the compression rate which is building the main range of the highest mountains on earth is only about $10 \mathrm{~mm} / \mathrm{yr}$ [Lyon-Caen and Molnar, 1985]. Similar rates are estimated across the Tien Shan, another major Asian mountain range [Molnar and Deng, 1984]. (Plate models tell us that the Indian subcontinent is moving northward into Asia at a speed of $\sim 50$ $\mathrm{mm} / \mathrm{yr}$, but most of this motion is taken up by the sideways escape of China [Lyon-Caen and Molnar, 1985].) Therefore, outside regions of substantial seismicity and/or young topography, intraplate deformation due to horizontal secular motions probably lies at or below the resolution of current space-geodetic experiments.

Zones of substantial intraplate seismicity are more intriguing. One is in the central United States near the town of New Madrid, Missouri, just south of the confluence of the Ohio and Mississippi Rivers, where faulting is active beneath the thick sedimentary cover. In 1811-12, a sequence of three very powerful earthquakes took place; these events had surface-wave magnitudes greater than eight and were felt over the entire eastern half of the continent [Nuttli, 1983]. The New Madrid seismic zone lies directly between the VLBI stations at Ft. Davis, Texas, and Westford, Massachusetts, and VLBI data on this baseline show an average closure rate of 5-10 mm/yr [Herring and Shapiro, 1985]. As Herring and Shapiro [1985] note, systematic measurement errors or local antenna motions may be responsible, but the observation has nevertheless prompted informal speculation that the seismic and geodetic observations are both manifestations of the same intraplate tectonics. The maximum compressive stress is indeed oriented in a northeast-southwest direction [Zoback and Zoback, 1980], and some estimates of the strain rates within the New Madrid seismic zone [Johnson and Nava, 1985] are high enough to make a causal relation 
plausible, but these rates depend critically on a poorly constrained earthquake recurrence time. The tectonics of the New Madrid region are controlled by very old (Precambrian) structures reactivated by intraplate stress [Braile et al., 1982]. Because the rate of topographic change associated with these features appears to be low, we estimate that the closure rate on the Westford-Ft.Davis baseline due to horizontal secular motion distributed across the eastern U.S. is probably less than $1 \mathrm{~mm} / \mathrm{yr}$.

\section{CONCLUSIONS}

Many geological and geophysical problems related to the various types of surface motion in Table 1 are currently being addressed by space-geodetic experiments. Space geodesy can be an effective tool for solving these problems only if critical measurements are made at accuracies not feasible by more conventional (and less expensive) techniques. In this paper, we have addressed the requirements for observing the subset of motions that are tangential to the earth's surface and persist for geologically significant intervals. Our conclusions can be summarized as follows:

- To contribute to the improvement of existing models of present-day motion among the major plates, the tangential components of relative velocities on interplate baselines must be resolved to an accuracy of $<3 \mathrm{~mm} / \mathrm{yr}$.

- Measuring the velocities between crustal blocks to $\pm 5 \mathrm{~mm} / \mathrm{yr}$ can place geologically useful constraints on the integrated deformation rates across continental plate-boundary zones, such as the western U.S.

- To detect the horizontal motions associated with the secular deformation of stable plate interiors, the tangential components on intraplate baselines must be resolved to an accuracy of $<1 \mathrm{~mm} / \mathrm{yr}$.

With regard to the second bullet, we wish to emphasize that baseline measurements in geologically complicated zones of deformation are useful only to the extent that the relationship of the endpoints to geologically significant crustal blocks is understood. Some antennas have a long history of participation in VLBI experiments, so that their motions in the VLBI reference frame are becoming well known; but they lie within complex zones of faulting, and their motions in kinematical frames fixed to local geology are not at all known. For example, the baseline rates for the Owens Valley Radio Observatory (OVRO) in California relative to the Westford, Massachusetts, and Ft. Davis, Texas, antennas have been measured to a precision of about $2 \mathrm{~mm} / \mathrm{yr}$ (T. Clark, personal communication, 1986). In our analysis of Basin and Range extension, we have assumed OVRO moves with the Sierra Nevada-Great Valley block, but unfortunately, it is separated from the Sierra Nevada by a major system of faults, one of which broke in the great 1872 Owens Valley earthquake. Until the position of OVRO is regularly resurveyed in a local geodetic network which includes stations planted firmly on the Sierra block, the geological implications of the VLBI data will remain in doubt. The establishment of local geodetic networks around major VLBI and SLR sites in active areas should receive high priority.

Acknowledgements. We thank C. DeMets and J. Goff for preprints and T. Clark, R. Gordon, T. Herring, and J. Sauber for helpful discussions. This research was sponsored by the Crustal Dynamics Project of the National Aeronautics and Space Administration under contracts NAG5-459 and NAS5-28572. 


\section{REFERENCES}

Agnew, D. C., et al., GPS measurements in central and southern California (abstract), Eos Trans. AGU, 68, 282, 1987.

Braile, L. W., G. R. Keller, J. W. Hinze, and E. G. Lidiak, An ancient rift complex and its relation to contemporary seismicity in the New Madrid seismic zone, Tectonics, 1, 225-237, 1982.

Chase, C. G., The n-plate problem of plate tectonics, Geophys. J. R. Astr. Soc., 29, 117-122, 1972.

Chase, C. G., Plate kinematics: the Americas, East Africa, and the rest of the world, Earth Planet. Sci. Lett., 37 , 353-368, 1978.

Christodoulidis, D. C., D. E. Smith, R. Kolenkiewicz, S. M. Klosko, M. H. Torrence, and P. J. Dunn, Observing tectonic plate motions and deformations from satellite laser ranging, J. Geophys. Res., 90, 9249-9264, 1985.

Christodoulidis, D. C., D. E. Smith, S. M. Klosko, J. W. Robbins, P. J. Dunn, and M. H. Torrence, Tectonic motion in western USA from satellite laser ranging, preprint, 1987.

Clark, T., J. Ryan, C. Ma, E. Himwich, D. Gordon, and A. Mallama, Geodesy by radio interferometry: measurements of vector site motions in the western U.S. and Alaska (abstract), Eos Trans. AGU, 67, 906, 1986.

Crouch, J. K., S. B. Bachman, and J. T. Shay, Post-Miocene compressional tectonics along the central California margin, in Tectonics and Sedimentation along the California Margin, edited by J. K. Crouch and S. B. Bachman, Pac. Sect. Soc. Econ. Paleontol. Mineral., 38, 37-54, 1984.

DeMets, C., R. G. Gordon, S. Stein, and D. F. Argus, A revised estimate of Pacific-North America motion and implications for western North America plate boundary zone tectonics, Geophys. Res. Lett., submitted, 1987.

Gawthrope, W. J., Seismicity and tectonics of the central California coastal region, in San Gregorio-Hosgri Fault Zone, California, edited by E. A. Silver and W. R. Normark, Calif. Div. Mines Geol. Spec. Rept. 137, 45-56, 1978.

Goff, J. A., E. A. Bergman and S. C. Solomon, Earthquake source mechanisms and transform fault tectonics in the Gulf of California, J. Geophys. Res., in press, 1987.

Golombeck, M. P., Geometry and rate of extension across the Pajarito fault zone, Espanola Basin, Rio Grande Rift, northern New Mexico, Geology, 9, 21-24, 1981.

Herring, T. A., and I. I. Shapiro, Geodesy by radio interferometry: stability of the North American plate, Eos Trans. $A G U, 66,848,1985$.

Herring, T. A., et al., Geodesy by radio interferometry: evidence for contemporary plate motion, J. Geophys. Res., 91, 8341-8347, 1986.

Johnson, A. C., and S. J. Nava, Recurrence rates and probability estimates for the New Madrid seismic zone, $J$. Geophys. Res., 90, 6737-6753, 1985.

Le Pichon, X., Sea-floor spreading and continental drift, J. Geophys. Res., 73, 3661-3697, 1968.

Lyon-Caen, H., and P. Molnar, Gravity anomalies, flexure of the Indian plate, and the structure, support and evolution of the Himalaya and Ganga Basin, Tectonics, 4, 513-538, 1985.

Lyzenga, G. A., K. S. Wallace, J. L. Fanselow, A. Raefsky, and P. M. Groth, Tectonic motions in California inferred from very long baseline interferometry observations, J. Geophys. Res., 91, 9473-9487, 1986.

Minster, J. B., T. H. Jordan, P. Molnar, and E. Haines, Numerical modelling of instantaneous plate tectonics, Geophys. J. R. Astr. Soc., 36, 541-576, 1974.

Minster, J. B., and T. H. Jordan, Present-day plate motions, J. Geophys. Res., 83, 5331-5354, 1978.

Minster, J. B., and T. H. Jordan, PMOTION: interactive software for computing RM2-predicted relative motions and uncertainties between CDP sites, NASA Crustal Dynamics Project, unpublished technical report, April, 1983.

Minster, J. B., and T. H. Jordan, Vector constraints on Quaternary deformation of the western United States east and west of the San Andreas Fault, in Tectonics and Sedimentation along the California Margin, edited by J. K. Crouch and S. B. Bachman, Pac. Sect. Soc. Econ. Paleontol. Mineral., 38, 1-16, 1984.

Minster, J. B., and T. H. Jordan, Vector constraints on western U.S. deformation from space geodesy, neotectonics and plate motions, J. Geophys. Res., 92, 4798-4804, 1987.

Molnar, P., and Q. D. Deng, Large earthquakes and average rate of deformation in Asia, J. Geophys. Res., 89, 6203-6228, 1984.

Nuttli, O. W., Average seismic source-parameter relations for mid-plate earthquakes, Bull. Seismol. Soc. Am., 73, $519-535,1983$

Savage, J. C., Strain accumulation in western United States, Ann. Rev. Earth Planet. Sci., 11, 11-43, 1983.

Savage, J. C., M. Lisowski, W. H. Prescott, and A. R. Sanford, Geodetic measurements of horizontal deformation across the Rio Grande Rift near Socorro, New Mexico, J. Geophys. Res., 85, 7215-7220, 1980.

Wallace, R. E., Patterns and timing of Late Quaternary faulting in the Great Basin province, and relation to some regional tectonic features, J. Geophys. Res., 89, 5763-5770, 1984.

Woodward, L. A., Rate of crustal extension across the Rio Grande Rift near Albuquerque, New Mexico, Geology, 5, 269-272, 1977

Zoback, M. L., and M. Zoback, State of stress in the conterminous United States, J. Geophys. Res., 85, 6113-6156, 1980. 